\title{
Tribological behavior of PTFE based single layer and double layer fabric composites
}

\author{
H. L. Li, Z. W. Yin, D. Jiang, L. Y. Jin, Y. Q. Cui \& J. Cao \\ State Key Laboratory of Mechanical Systems and Vibration, \\ Shanghai Jiao Tong University, China
}

\begin{abstract}
Three different PTFE based fabric composites were prepared, and the tribological behaviors of these composites under different loads and speeds were studied. The morphologies of the worn surface and the debris were analyzed by means of scanning electron microscopy. In addition, a laser microscopy (3D profile measurements) was used to analyze the wear volume of the fabric composites. The results demonstrated that the composite weave structure and shape of the yarn have an influence on the tribological behavior of PTFE based composites. Generally, the wear resistance of the single layer fabric composites is better than that of the double layer fabric composites, and the friction coefficient of tape yarn fabric composites is lower than that of the multifilament yarn fabric composites. In addition, loads and speeds also play an important influence on the tribological behavior of the composites. For all samples, the friction coefficient decreased with increasing load. However, with the increase of the speed, the friction coefficient of all samples first increased and then decreased.

Keywords: polymer-matrix composite, friction, wear, single layer, double layer, PTFE, Nomex, cotton, bearing.
\end{abstract}

\section{Introduction}

Fabric composites play an important role in materials and mechanical engineering, not only for their ease in manufacturing and low unit cost but also for their potentially excellent tribological performance in engineered forms. Therefore, they are very attractive materials for use as advanced bearing liner materials. Hybrid PTFE based fabric composites, which are woven out of PTFE and other high performance fibers (such as Kevlar, Nomex, cotton etc.), are one of the most 
popularly used bearing liner materials. The good lubrication of the PTFE fiber side was used as the friction surface, and the other side fiber, with its good mechanical properties or adhesive properties, was used as the binding surface [1].

A lot of research on particle-filled PTFE based composites revealed their significant potential in producing materials with good comprehensive friction properties [2-5]. Tanaka and Kawakami [3] researched the PTFE-based composites and found the load-supporting action and the prevention of large-scale destruction of the banded structure of the PTFE matrix at frictional surfaces contribute to the wear-reducing action of the fillers. Conte et al. [6] studied the role of crystallinity on wear behavior of PTFE composites and presented that fillers content and type have an effect on the crystallinity and thermal properties of PTFE composites and then influence on the formation and regeneration of transfer film. Su et al. $[7,8]$ investigated the tribological properties of nano- $\mathrm{TiO}_{2}$ and nano-ZnO-filled hybrid glass/PTFE fabric composites, and the results indicated that the incorporation of $\mathrm{TiO}_{2}$ and $\mathrm{ZnO}$ nanoparticles could significantly improve the wear resistance of the composites. Zhang et al. [9] studied the influence of nano- $\mathrm{TiO}_{2}$ and modified nano- $\mathrm{TiO}_{2}$ on the tribological behavior of hybrid PTFE/cotton fabric. The incorporation of unmodified and modified nano$\mathrm{TiO}_{2}$ was found to significantly reduce the wear rate of the fabric composite, but it cannot reduce the friction coefficient.

Recently, many researchers [10-13] have reported that weave structures exhibit an important influence on the tribological properties of hybrid fabric composites. Rattan et al. [12] studied the effect of carbon fabric weave on the low amplitude, oscillating wear performance of polyetherimide composites. The retention capability of pulverized fiber debris in the composite surfaces dominated the wear resistance of the fabric composites. A plain weave was the most effective in retaining debris, resulting in the highest wear resistance, while satin was the least effective in this aspect, leading to the poorest performance. Rattan and Bijwe [11] investigated the influence of fabric weave and processing parameters on performance properties and erosive wear, finding that the seepage capability and resin retention significantly influence the strength and tribological properties of fabric composites. Rattan et al. [13] optimized the carbon fabric weave of polyetherimide composites with respect to the optimal combination of strength and tribo-performance in adhesive wear mode. Twill weave has proven to be the most suitable for the optimal combination of strength, modulus and triboperformance. In general, weave structure determines the strength, seepage capability and resin retention of the composites; thus, weave structures greatly influence the tribological properties of fabric composites. Unfortunately, whether plain, twill or satin, the current focus of attention is only the different structure of single layer fabric. Few studies have been performed to investigate the tribological behavior of double layer fabric composites. Therefore, this work is a comparative study of the tribological behavior of hybrid PTFE based single and double layer fabric composites. 


\section{Experimental section}

\subsection{Materials and specimen preparation}

The PTFE based fabric composites used in this study was woven from PTFE fibers and Nomex/cotton fibers, and the different fabric composites names are defined in Table 1. Meanwhile, a picture of the fabric composites is shown in Fig. 1. As shown in Fig. 1, the two sides of the fabric have different proportions of fibers. For composites I, the front face was tape yarn PTFE fiber and was always used as a friction surface. The back face was rich in multifilament yarn Nomex fiber and was used as a binding surface. For composites II, the front face was multifilament yarn PTFE fiber and was always used as a friction surface. The back face was rich in multifilament yarn Nomex fiber and was used as a binding surface. For composites III, the front face was rich in PTFE fiber and was always used as a friction surface. The back face was rich in cotton fiber and was used as a binding

Table 1: $\quad$ Properties of fabric composites.

\begin{tabular}{lll}
\hline Composites name & Fabric & Weave structure \\
\hline Composites I & Tape yarn PTFE/multifilament yarn Nomex & Double layer \\
Composites II & Multifilament yarn PTFE/multifilament yarn Nomex & Double layer \\
Composites III & Tape yarn PTFE/multifilament yarn cotton & Single layer \\
\hline
\end{tabular}

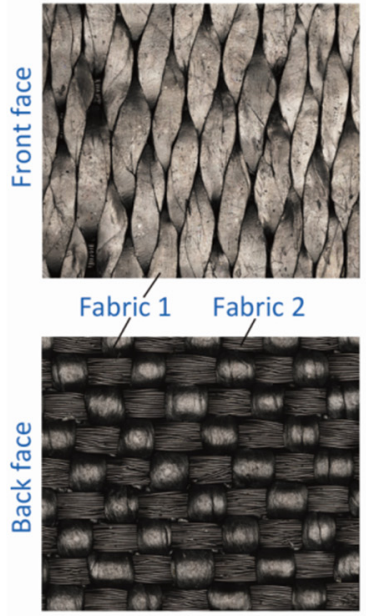

(a)

Fabric 1--Tape yarn PTFE fabric

Fabric 3-- Multifilament yarn PTFE fabric

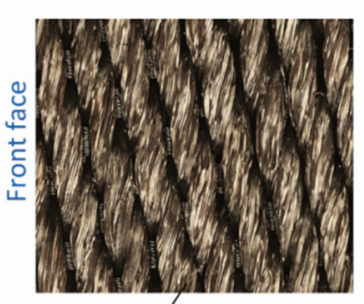

Fabric 3 Fabric 2

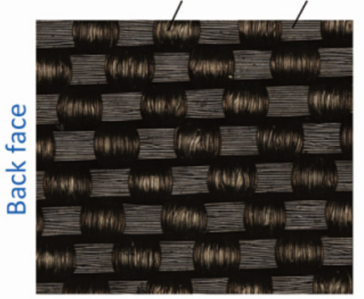

(b)

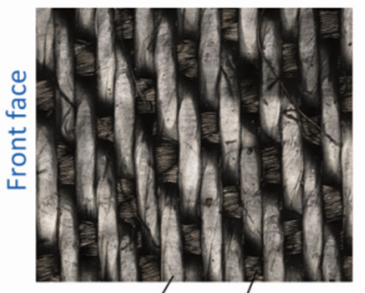

Fabric 1 Fabric 4

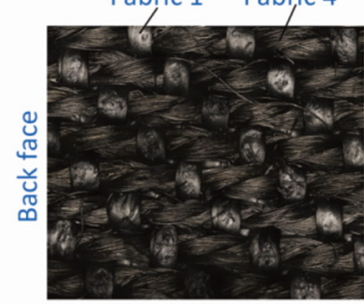

(c)

Fabric 2--Multifilament yarn nomex fabric Fabric 4--Multifilament yarn cotton fabric

Figure 1: Image of the different fabric composites: (a) fabric composites I, (b) fabric composites II and (c) fabric composites III. 
surface. In this way, the low friction of fibers and high strength of fibers were combined to a great extent [1]. The fillers used in this study are commercially available, and the material properties are listed in Table 2.

Table 2: $\quad$ Properties of nano- $\mathrm{Si}_{3} \mathrm{~N}_{4}$ and submicron size $\mathrm{WS}_{2}$.

\begin{tabular}{lll}
\hline Materials & $\mathrm{Si}_{3} \mathrm{~N}_{4}$ & $\mathrm{WS}_{2}$ \\
\hline Grain size $(\mathrm{nm})$ & $80-100$ & 600 \\
Purity $(\%)$ & 99.9 & 99.9 \\
Specific surface area $\left(\mathrm{m}^{2} / \mathrm{g}\right)$ & 71 & 3.214 \\
Tap density $\left(\mathrm{g} / \mathrm{cm}^{3}\right)$ & 1.14 & 2.04 \\
Bulk density $\left(\mathrm{g} / \mathrm{cm}^{3}\right)$ & 0.49 & 0.44 \\
\hline
\end{tabular}

Due to the very small diameter of nano- $\mathrm{Si}_{3} \mathrm{~N}_{4}$, nano- $\mathrm{Si}_{3} \mathrm{~N}_{4}$ has a much higher surface area-to-volume ratio than do larger-sized particles, and their surface energy is high. Thus, the adhesive force between the nanoparticles is strong, and the particles are easily agglomerated [8]. To prevent agglomeration of the particles, ultrasonic vibration was used to disperse the nano- $\mathrm{Si}_{3} \mathrm{~N}_{4}$ and submicron size $\mathrm{WS}_{2}$ particles in a modified polyimide resin. The hybrid PTFE based fabrics were ultrasonically cleaned in an acetone bath for $1 \mathrm{~h}$, boiled $30 \mathrm{~min}$ in distilled water, dried in an oven at $80^{\circ} \mathrm{C}$ for $1 \mathrm{~h}$, and then the dried hybrid PTFE/Kevlar fabrics were weighed by a precision balance (accuracy: $0.1 \mathrm{mg}$ ). The fillers were mixed uniformly with modified polyimide adhesive resin at the proper mass fractions with the assistance of ultrasonic stirring. Afterwards, the hybrid PTFE based fabrics were immersed in the mixed adhesive containing the fillers. Subsequently, the immersed fabrics were dried in a nitrogen-purged environment at a rate of $50^{\circ} \mathrm{C} / \mathrm{h}$ to $130^{\circ} \mathrm{C}$, where they were held for $1 \mathrm{~h}$. The specimens were then cooled at a rate of $50^{\circ} \mathrm{C} / \mathrm{h}$ back to room temperature. After this, the specimens were weighed and calculated the relative mass fraction of fabrics. The immersion was repeated several times until the relative mass fraction of fabrics was $70 \pm 5 \%$. And then, a laboratory press was used to consolidate the fabrics under pressure of $5 \mathrm{MPa}$ at $210^{\circ} \mathrm{C}$ for $30 \mathrm{~min}$. Finally, the filled PTFE based fabric composites were affixed onto the 440c stainless steel using the modified polyimide adhesive resin and then cured at $210^{\circ} \mathrm{C}$ for $15 \mathrm{~min}$ under pressure of $0.2-0.3 \mathrm{MPa}$.

\subsection{Tribological test}

Tribological tests were performed using a pin-on-disc tribometer (RTEC MFT$5000)$ under dry friction conditions. All of the experiments were performed under laboratory conditions (temperature, $\mathrm{T}=25^{\circ} \mathrm{C}$, relative humidity $\sim 50 \%$ ). Fig. 2 shows the schematics of the test assembly. In the pin-on-disc tester, a stationary steel pin slid against a rotating steel disc that was affixed with the PTFE based fabric composite specimens. The flat-ended bearing steel pin (diameter of $4 \mathrm{~mm}$ ) was secured to the load arm with a chuck. The distance between the center of the pin and the center of the disc was $16 \mathrm{~mm}$. The pin remained over the disc with two 


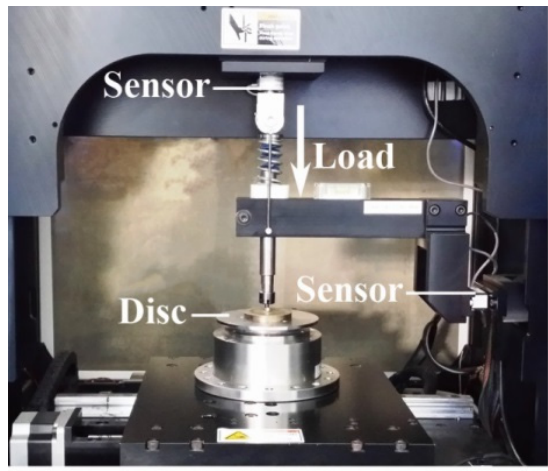

(a)

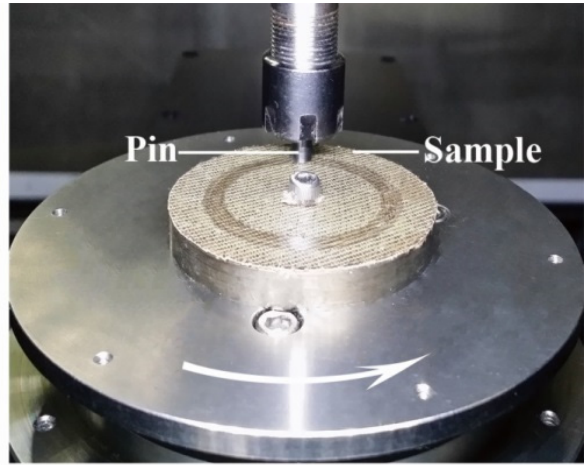

(b)

Figure 2: The schematics of the test assembly.

degrees of freedom: the vertical one for normal load application by direct contact with the disc and the horizontal one for friction measurement.

Sliding was performed under dry friction conditions at varied sliding speeds that ranged between 0.0017 and $1.6755 \mathrm{~m} / \mathrm{s}$, normal load that ranged between 12.56 and $628 \mathrm{~N}$. For friction coefficient and wear rate measurement test the sliding distance were $3 \mathrm{~m}$ and $3600 \mathrm{~m}$, respectively. The normal load and friction force were measured by normal force sensor (range: 50 to $5000 \mathrm{~N}$, resolution: $0.25 \mathrm{~N}$ ) and friction force sensor (range: 1 to $100 \mathrm{~N}$, resolution: $0.005 \mathrm{~N}$ ), and the frequency of sampling is $1000 \mathrm{~Hz}$. The friction coefficient $\mu$ of the specimen were calculated by the relationship $\mu=F / P$, where $F$ is the friction force $(N), P$ is the normal load (N). At the end of each test, the wear volume loss of the PTFE based fabric composites was obtained by measuring the cross-sectional area of the wear scar and the wear depth using the KEYENCE VK-X200 laser microscopic 3D and profile measurement apparatus (accuracy: $0.012 \mu \mathrm{m}$ ). To ensure statistically relevant results, each sample was taken three cross sectional measurements equispaced distributed along the wear scar to determine the general average of volume loss occurring. Meanwhile, in order to reduce the influence of initial surface characteristics on the measurement accuracy the average height of the initial surface were used as the measuring datum (base line). The wear data were finally presented as the wear rates in well-known units $\left(\mathrm{m}^{3} / \mathrm{Nm}\right)$. The uncertainty of volume loss $\left(u_{v}\right)$ is determined by eqn (1) [14]:

$$
U_{v}=\frac{2 \pi R}{\sqrt{N}} \sigma_{A} .
$$

where $\mathrm{R}$ is the nominal radius of the wear scar, $\mathrm{N}$ is the number of scans and $\sigma_{A}$ is the standard deviation of the measured areas. The schematic diagram of the measurement technique is shown in Fig. 3.

Prior to the tests, the pins were polished using 1000 grit paper to an average roughness of $\mathrm{Ra}=0.1-0.2 \mu \mathrm{m}$, and then the pins were cleaned with acetone and dried with a laboratory wipe. Each experiment used a new pin and a new sample. To ensure statistically relevant results, each experiment was repeated three times.

After the experiments, the wear scar of the PTFE based fabrics and its debris was examined by Scanning Electron Microscopy (SEM). 


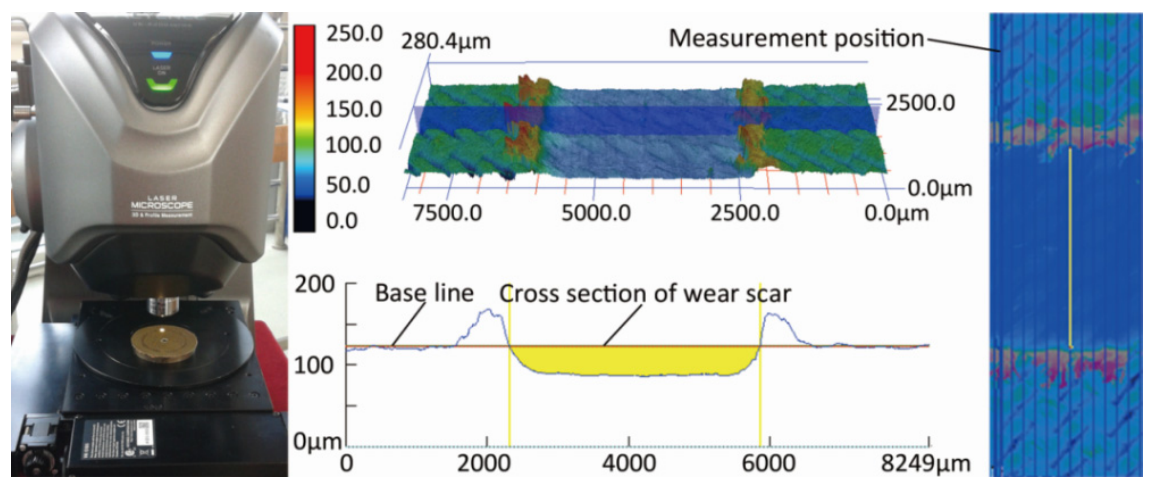

Figure 3: $\quad$ Schematic diagram of the measurement technique.

\section{Results and discussion}

\subsection{Friction and wear properties}

Figure 4 shows the variation of the friction coefficient of PTFE based fabric composites under the different loads (speed: $0.1675 \mathrm{~m} / \mathrm{s}$ ). It can be observed from the figure that the load greatly influences the friction coefficient of the hybrid PTFE based fabric composites. The friction coefficient of the entire hybrid PTFE based fabric composites decrease with increasing load. For composite I with the increase of the load the friction decreased from 0.175 to 0.056 . For composite II with the increase of the load the friction decreased from 0.179 to 0.059 . For composite III with the increase of the load the friction decreased from 0.137 to 0.055 .

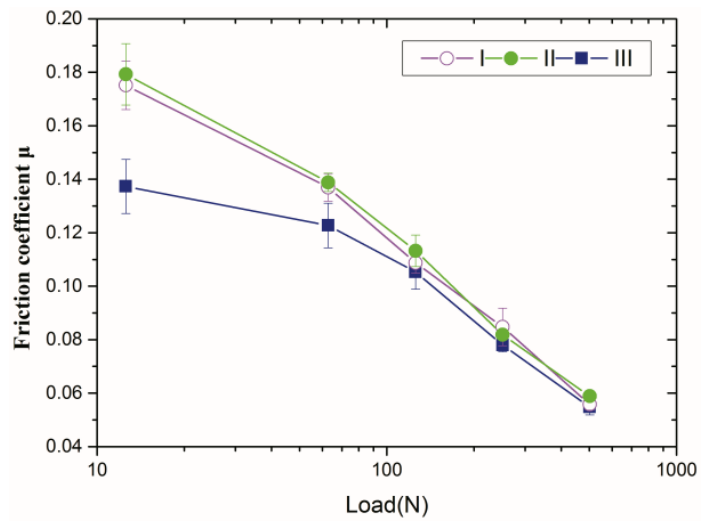

Figure 4: Variation of the friction coefficient and its standard deviation of the PTFE based fabric composites under the different loads (speed: $0.1675 \mathrm{~m} / \mathrm{s}$ ). 
Figure 5 shows the variation of the friction coefficient of PTFE based fabric composites under the different sliding speeds (load: 628N). In contrast, the friction coefficient of the entire hybrid PTFE based fabric composites first increased and then decreased with increasing sliding speed. With regard to a decrease in coefficient of friction, it is often believed that with the increase of speed, the temperature at the friction interface between composite and counterpart pin increased. And then, the adhesive resins become soft and the surfaces of the composites are polished rapidly, finally, leading to a decrease in the friction coefficient.

The friction coefficients and wear rates of the hybrid PTFE based fabric composites are comparatively shown in Fig. 6. It can be observed from the figure that the wear resistance of the single layer fabric composites is better than that of the double layer fabric composites. In addition, for double layer fabric composites

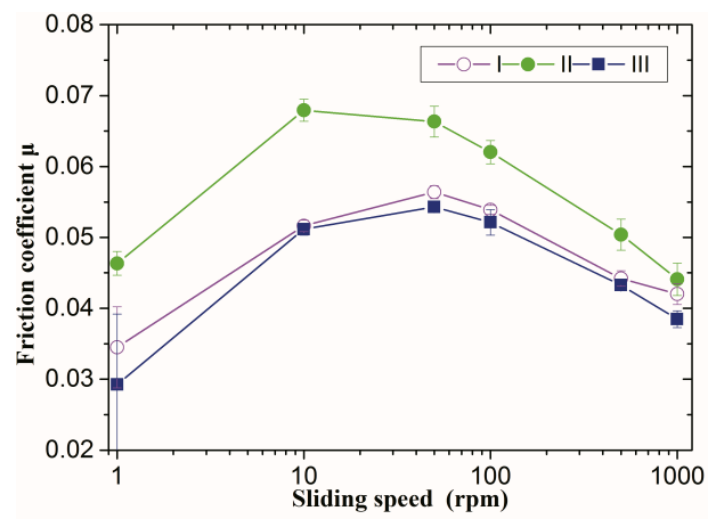

Figure 5: Variation of the friction coefficient and its standard deviation of the PTFE based fabric composites under the different speeds (load: $628 \mathrm{~N}$ ).

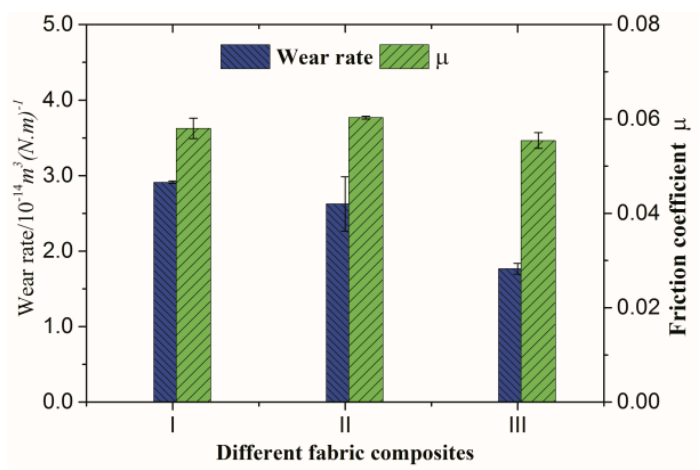

Figure 6: Variation of the friction coefficient/wear rate and its standard deviation of the PTFE based fabric composites (speed: $1 \mathrm{~m} / \mathrm{s}$, load: $377 \mathrm{~N})$. 
the wear rate of composites II is less than the composites I and the friction coefficient of composites II is greater than the composites I. This means that the wear resistance of multifilament yarn fabric composites is better than that of the tape yarn fabric composites and the antifriction properties of tape yarn fabric composites is better than the multifilament yarn fabric composites. Reasons for these phenomena are that for double layer fabric composites and tape yarn fabric composites, nanoparticle and resin penetration into the fiber become more difficult, especially in the double layer tape yarn fabric composites. Meanwhile, the front face of double layer fabric composites is full of PTFE fibers. It is well known that the adhesion and wear resistance of PTFE are very poor, so the fibermatrix interfacial adhesive strength and the composites wear resistance worsens.

\subsection{SEM observations of the worn surfaces}

Figures 7(a)-(i) show the SEM images of the original and worn surface of PTFE based fabric composites. It can be seen from figures 7(a)-(f) that a large number of PTFE and Nomex fibers significantly peel, and there are many long and deep cracks on the worn surface, which is indicative of severe wear. Figures 7(h) and
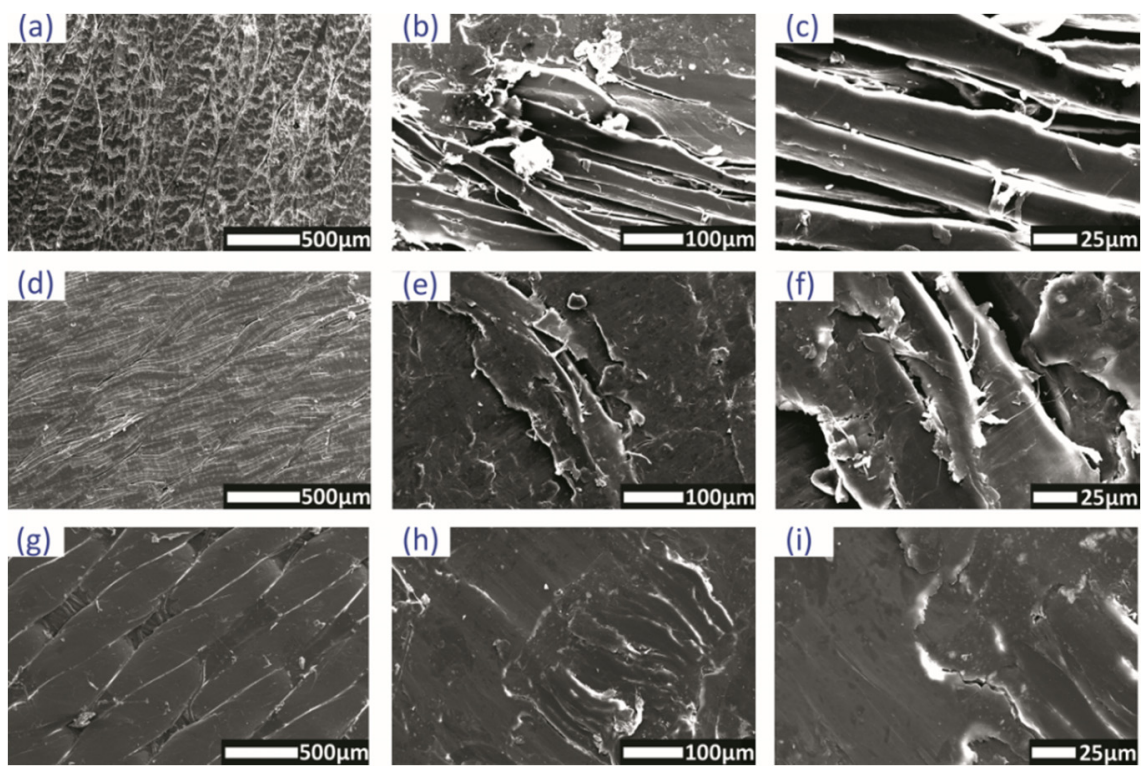

Figure 7: Scanning electron micrographs of the surfaces of hybrid PTFE based fabric composites(speed: $1 \mathrm{~m} / \mathrm{s}$, load: $377 \mathrm{~N}$ ): (a) original surface of composites I, (b) worn surface of composites I, (c) magnification of (b), (d) original surface of composites II, (e) worn surface of composites II, (f) magnification of (e), (g) original surface of composites III, (h) worn surface of composites III, (i) magnification of (h). 
(i) show the SEM images of the worn surfaces of composites III. The worn surface of III is quite smooth, and the fibers are strongly combined with the matrix. This observation indicates that the adhesive strength between the cotton fibers and the matrix is better than the Nomex fibers and the matrix. Good adhesive properties between fibers and matrix result in the strengthening of the mechanical properties of the fabric composite. Therefore, the wear resistance is significantly improved.

\subsection{SEM examination of the wear debris}

Debris is a product of the frictional experiment, and analyzing debris is helpful to understand the tribological mechanisms. Figure 8 shows the SEM images of the wear debris of hybrid PTFE based fabric composites. It can be observed from Fig. 8(a) and (b) that double layer fabric composites generate debris that mainly consists of large flake and lumpy slabs. Fig. 8(c) shows the wear debris of single layer fabric composites that mainly consists of flakes and ribbon wear debris. That is, three kinds of PTFE based composites under the test conditions are formed large debris. Moreover, large wear debris cannot easily fill in the grooves on the fabric surface, and hence, they pile up during repeated sliding and subsequently are discarded as debris.
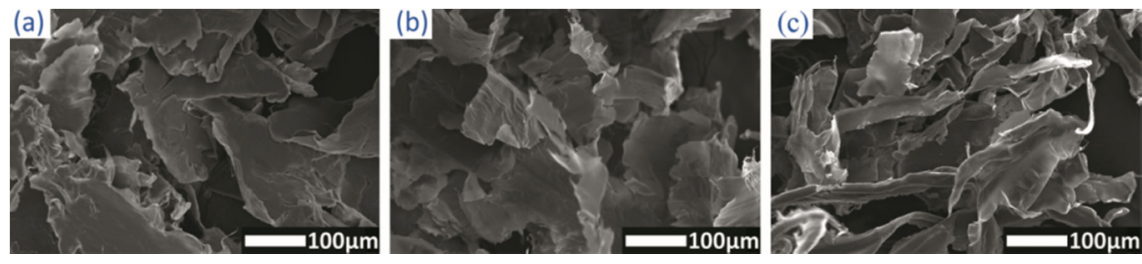

Figure 8: SEM images of the wear debris of hybrid PTFE based fabric composites (speed: 1m/s, load: $377 \mathrm{~N}$ ): (a) composites I, (b) composites II, and (c) composites III.

\section{Conclusion}

This work presents investigations on the tribological behavior of hybrid PTFE based single layer and double layer fabric composites samples against bearing steel at dry friction conditions. The following conclusions can be drawn from the present study:

a) It was found that under the experimental conditions, the wear resistance of the single layer fabric composites is better than that of the double layer fabric composites.

b) Under the experimental conditions, the friction coefficient of tape yarn fabric composites is lower than that of the multifilament yarn fabric composites.

c) Loads play an important influence on tribological behavior of the composites. For all samples, the friction coefficient decreased with increasing load.

d) Speeds also play an important influence on tribological behavior of the composites. For all samples, with the increase of the speed the friction coefficient of all samples first increased and then decreased. 


\section{Acknowledgements}

The authors gratefully acknowledge financial support from the National Project 863 (Grant N0. 2014BAF08B00). The authors also thank Edison Wu of Keyence (China) Co. Ltd for technical support with the KEYENCE VK-X200 laser microscopic 3D and profile measurement apparatus operation.

\section{References}

[1] Zhang, H. J., Zhang, Z. Z., Guo, F., Wang, K., Jiang, W., Enhanced wear properties of hybrid PTFE/cotton fabric composites filled with functionalized multi-walled carbon nanotubes. Materials Chemistry and Physics, 116, pp. 183-190, 2009.

[2] Biswas, S. K., Vijayan, K., Friction and wear of PTFE-a review. Wear, 158, pp. 193-211, 1992.

[3] Tanaka, K., Kawakami, S., Effect of various fillers on the friction and wear of PTFE-based composites. Wear, 79, pp. 221-234, 1982.

[4] Sawyer, W. G., Freudenberg, K. D., Bhimaraj, P., Schadler, L. S., A study on the friction and wear behavior of PTFE filled with alumina nanoparticles. Wear, 254, pp. 573-580, 2003.

[5] Li, H. L., Yin, Z. W., Jiang, D., Huo, Y. J., Cui, Y. Q., Tribological behavior of hybrid PTFE/Kevlar fabric composites with nano- $\mathrm{Si}_{3} \mathrm{~N}_{4}$ and submicron size $\mathrm{WS}_{2}$ fillers. Tribology International, 80, pp. 172-178, 2014.

[6] Conte, M., Pinedo, B., Igartua, A., Role of crystallinity on wear behavior of PTFE composites. Wear, 307, pp. 81-86, 2013.

[7] Su, F. H., Zhang, Z. Z., Liu, W. M., Friction and wear behavior of hybrid glass/PTFE fabric composite reinforced with surface modified nanometer ZnO. Wear, 265, pp. 311-318, 2008.

[8] Su, F. H., Zhang, Z. Z., Liu, W. M., Tribological behavior of hybrid glass/PTFE fabric composites with phenolic resin binder and nano- $\mathrm{TiO}_{2}$ filler. Wear, 264, pp. 562-570, 2008.

[9] Zhang, H. J., Zhang, Z. Z., Guo, F., Liu, W. M., Friction and wear behavior of the hybrid PTFE/cotton fabric composites filled with $\mathrm{TiO}_{2}$ nanoparticles and modified $\mathrm{TiO}_{2}$ nanoparticles. Polymer Engineering \& Science, 49, pp. 115-122, 2009.

[10] Cornelissen, B., Sachs, U., Rietman, B., Akkerman, R, Dry friction characterisation of carbon fibre tow and satin weave fabric for composite applications. Composites Part A, 56, pp. 127-135, 2014.

[11] Rattan, R., Bijwe, J., Carbon fabric reinforced polyetherimide composites: Influence of weave of fabric and processing parameters on performance properties and erosive wear. Materials Science and Engineering: A, 420, pp. 342-350, 2006.

[12] Rattan, R., Bijwe, J., Fahim, M., Influence of weave of carbon fabric on low amplitude oscillating wear performance of Polyetherimide composites. Wear, 262, pp. 727-735, 2007. 
[13] Rattan, R., Bijwe, J., Fahim, M., Optimization of weave of carbon fabric for best combination of strength and tribo-performance of polyetherimide composites in adhesive wear mode. Wear, 264, pp. 96-105, 2008.

[14] Colbert, R. S., Krick, B. A., Dunn, A. C., Vail, J. R., Argibay, N., Sawyer, W. G., Uncertainty in Pin-on-Disk Wear Volume Measurements Using Surface Scanning Techniques. Tribology Letters, 42, pp. 129-131, 2011. 